\title{
A Experiência do Serviço Social do Instituto da Criança- Icr - HCFMUSP Junto aos Jovens com Hiv em Seu Processo de Transferência para um Ambulatório de Infectologia Adulto
}

\author{
Oliveira, Vivian Silva de \\ Instituto da Criança do Hospital das Clínicas da Faculdade de Medicina da Universidade de São \\ Paulo — viviss82@yahoo.com.br
}

\begin{abstract}
Introdução: o presente trabalho enfatiza a experiência do Serviço Social em um trabalho em rede entre as equipes multiprofissionais do Ambulatório de Infectologia Pediátrico (ICr-HC) e do Ambulatório de Infectologia Adulto (HCFMUSP) entre 2010 e 2011. Através da constatação que um número significativo de jovens transferidos para o ambulatório de infectologia adulto do $\mathrm{HC}$ em anos anteriores a 2010, demoravam a comparecer às consultas ou abandonavam o tratamento. Objetivos: Garantir a continuidade do atendimento junto aos jovens em processo de transferência. Metodologia: o enfoque utilizado foi quali-quantitativo. Foram detectados 28 jovens na faixa etária entre 18 e 20 anos com diagnóstico de HIV atendidos no ambulatório de infectologia pediátrica do ICr-HC, no ano de 2011. Os instrumentos utilizados pelo serviço social no processo de transferência foram: questionários semiestruturados de condições sócio-economicas e de vida dos jovens e grupos operativos realizado no ambulatório de infectologia de adulto. Resultados: dos 28 jovens detectados, 24 participaram do processo de transferência. Destes, 22 jovens permaneceram em acompanhamento no ambulatório de infectologia adulto do $\mathrm{HC}$ e 2 optaram pela realização do tratamento em outros serviços de especialidade, 4 jovens não foram localizados. a intervenção contribuiu para minimizar os sentimentos de insegurança e medo presente no momento da transferência para outro local de tratamento. Sentimentos de superação de obstáculos e mudanças do ciclo de vida (da adolescência para a fase adulta) estiveram presentes durante a implementação das atividades. de acordo com as informações presentes nos questionários sócio-economicos podese constatar a abordagem favoreceu o despertar para a necessidade de construção da autonomia dos jovens envolvidos. Considerações Finais: a experiência do Serviço Social diante dos jovens aponta a importância das ações desenvolvidas, uma vez que 24 jovens deram continuidade ao seu tratamento, fato este fundamental para a qualidade e expectativa de vida dos mesmos.
\end{abstract}

Palavras-chave: Serviço Social, Instituto da Criança HCFMUSP, Jovens/HIV-Aids, Transferência, Ambulatório de infectologia adulto HC

Oliveira, Vivian Silva de. A Experiência do Serviço Social do Instituto da Criança- Icr - HCFMUSP Junto aos Jovens com Hiv em Seu Processo de Transferência para um Ambulatório de Infectologia Adulto. In: Anais do Congresso

Internacional de Humanidades \& Humanização em Saúde [= Blucher Medical Proceedings, num.2, vol.1]. São Paulo: Editora Blucher, 2014. ISSN 2357-7282

DOI 10.5151/medpro-cihhs-10386 